\title{
Alcohol and drug use disorders among adults with ADHD: Prevalence and associations with ADHD symptom severity and emotional dysregulation.
}

Espen ANKER ( $\nabla$ espen.anker@online.no )

Locus Coeruleus https://orcid.org/0000-0003-4960-1715

Jan Haavik

Universitetet i Bergen

Trond Heir

Universitetet i Oslo

Research article

Keywords: ADHD, ASRS, deficient emotional self-regulation, emotional dysregulation, substance use disorder (SUD), alcohol use disorder (AUD), drug use disorder (DUD)

Posted Date: September 23rd, 2019

DOl: https://doi.org/10.21203/rs.2.14798/v1

License: (c) (i) This work is licensed under a Creative Commons Attribution 4.0 International License. Read Full License 


\section{Abstract}

Background High risk of substance use disorders (SUD) in people with ADHD calls for exploratory research. The aim of this study was to estimate the prevalence of alcohol use disorder (AUD) and drug use disorder (DUD) in a clinical sample of adults with ADHD, and to examine their association with ADHD symptom severity and emotional dysregulation (ED).

Methods The study sample consisted of patients who were admitted to a private psychiatric outpatient clinic in Oslo between 2014 and 2018. Out of 612 patients diagnosed with ADHD, 585 (96.5\%) agreed to participate in the study. ADHD was diagnosed according to DSM- 5 criteria. AUD and DUD were diagnosed using the Mini International Neuropsychiatric Interview (M.I.N.I.). ADHD severity was assessed by the Adult ADHD Self Report Scale (ASRS). Emotional Dysregulation (ED) was assessed by the eight-item version of Barkley's Current Behavior Scale - Self Report (CBS-SR).

Results The 12-month prevalence of AUD and DUD was $5.3 \%$ and $13.7 \%$, respectively. The lifetime prevalence was $12.0 \%$ for AUD and $27.7 \%$ for DUD. A history of DUD, but not AUD, was positively associated with hyperactivity-impulsivity ADHD core symptoms, as well as ED.

Conclusions The prevalence of lifetime DUD among patients with ADHD is high and associated with higher levels of hyperactivity-impulsivity symptoms, as well as ED. It is important to consider comorbid DUD in adult ADHD patients, particularly among individuals with high levels of hyperactivity-impulsivity ADHD core symptoms or ED.

\section{Background}

Attention Deficit Hyperactivity Disorder (ADHD) is a life-span neuropsychiatric disorder with core symptoms of inattention, hyperactivity and impulsivity (1). ADHD is caused by a multitude of additive and interactive genetic and environmental factors operating in a highly complex manner $(2,3,4)$.

The prevalence of ADHD in the general adult population is estimated to be $3 \%-5 \%(5,6)$. ADHD is a dimensional diagnosis where attention deficits and hyperactivity-impulsivity may appear in various degrees and combinations (7).

The co-occurrence of ADHD and substance use disorders (SUD) such as alcohol use disorder (AUD) or drug use disorder (DUD) has been studied in a variety of clinical and research settings. Overall, there is an earlier onset and elevated risk of SUD in people with ADHD (6,8-17), but the direction of causality, underlying mechanisms and clinical implications of the strong association between ADHD and SUD are still unclear.

It is well documented that many patients with ADHD are striving to regulate negative emotions (18-20), and may be quick to anger, easily frustrated and emotionally over-excitable, a symptom cluster defined as 
Emotional Dysregulation (ED) $(21,22)$. Although ED may be understood as a transdiagnostic factor in the development of psychopathology (23) it appears to be specifically related to impulsivity (24).

ED has been found to be associated with SUD in children and adolescents with ADHD (25). The strong relationship between ADHD and ED (18-20) makes it challenging to determine whether it is ADHD severity per se or concurrent ED that is most strongly related to SUD.

The aim of the present study was to estimate the prevalence of AUD and DUD in a clinical sample of adults diagnosed with $A D H D$, and to examine their associations with ADHD symptom severity and ED.

\section{Methods}

\section{Participants}

The study sample consisted of adult patients, age range from 18 to 69 , who fulfilled the criteria for ADHD. They were admitted to a psychiatric clinic in Oslo, Norway, which was specialized in psychiatric examinations and treatment of ADHD. Recruitment was conducted in the years between 2014 and 2018. During these years, a total of 612 patients were found fulfilling the diagnostic criteria of ADHD and were asked to participate in the study. Sixty five percent of patients assessed were self-referred, and $35 \%$ were referred by general physicians, psychiatrists, neurologists or neuropsychologist.

Out of 612 patients with ADHD, 585 (95.6\%) gave their written consent to participate and were included in the study. The study was approved by the Regional Medical Ethics Committee, South-East D, Norway, 2015/426.

Assessments were carried out in accordance with ethical standards, and the principals of the Declaration of Helsinki were followed.

None of the authors have any competing interests.

\section{Measures}

A semi-structured psychiatric examination using DIVA 2.0 (26) was undertaken by a psychiatrist for all patients included in the study. A clinical diagnosis of ADHD was provided according to the diagnostic manual DSM-5 (1).

Information about age, gender, current marital/cohabitant status, and whether the participant was living with children, was recorded. Educational level was categorized by number of years in education; 12 years or less, 13-15 years, or more than 15 years. Work participation was categorized as 'yes' if work was reported as the main source of income.

Alcohol use disorder (AUD) and drug use disorder (DUD) were diagnosed using the specific module of the Mini International Neuropsychiatric Interview (M.I.N.I.), Norwegian Translation Version 6.0.0, according to Diagnostic and Statistical Manual of Mental Disorders, Fourth Edition (DSM-IV) criteria. $(27,28)$. 
Dependence and abuse were merged into "use" disorder as in M.I.N.I. version 7.0 / DSM-5, and questions were both restricted to last 12 months and related to lifetime.

ADHD symptom severity was measured using the Adult ADHD Self-Report Scale (ASRS) Symptom Check List, v1.1 by WHO 2007. The ASRS is a reliable and valid screening instrument for evaluating ADHD in adults (29). This 18-item version yields a score ranging from 0 to 72 points. We recorded subdivisions of the ASRS questionnaire, as inattentive items (item 1-4 and 7-11) and hyperactive/impulsivity items (item 5,6 , and 12-18) separately (30).

ED was assessed by a questionnaire with eight items from the 99 items Current Behavior Scale - Self Report (CBS-SR) questionnaire $(31,32,33)$. This 8-item version yields a score ranging from 0 to 24 points (Table 1).

\section{Statistical analysis:}

We performed chi-square tests or t-tests to compare sociodemographic characteristics between women and men. We used logistic regression analyses to examine associations between alcohol and drug use disorders as dependent variables and ADHD symptom severity and ED as independent variables. All tests were two-tailed, and differences were considered significant if $p<0.05$. All statistical analyses were done using the software package IBM 2016 SPSS version 22.

\section{Results}

Table 2 shows sociodemographic and clinical characteristics of men $(n=317)$ and women $(n=268)$ in the study. More women than men were living with children and women reported higher levels of ADHD symptoms and ED compared to men.

Table 3 shows the 12-month prevalence and lifetime prevalence of AUD and DUD in men and women. Both men and women had considerable higher prevalences of DUD than AUD, and men had higher prevalences of both AUD and DUD compared to women.

In the total sample $27.7 \%(n=162)$ of the participants had a history of lifetime DUD. Among these participants, the frequency of drug abuse was: amphetamine $69.1 \%(n=112)$, cannabis $61.7 \%(n=100)$, cocaine or ecstasy $26.5 \%(n=43)$, benzodiazepines $26.5 \%(n=43)$, heroin or other opioids $10.5 \%(n=17)$ and unspecified drugs $16.0 \%(n=26)$.

Tables 4 and 5 show associations between lifetime SUD and clinical characteristics including hyperactivity-impulsivity and ED. Lifetime AUD was not significantly associated with the levels of ADHD symptoms or ED when adjusted for gender and age (Table 4). In contrast, lifetime DUD was significantly associated with both hyperactivity- impulsivity and ED (Table 5). 


\section{Discussion}

In our clinical sample of adults with ADHD we observed a 12-month prevalence of $5.3 \%$ for AUD and $13.7 \%$ for DUD. The lifetime prevalence was $12.0 \%$ for AUD and $27.7 \%$ for DUD. All prevalence rates were higher for men than for women.

The 12-month prevalence of AUD was similar to the general population prevalence in Norway and US $(34,35,36)$. In contrast, the 12 -month prevalence of DUD $(13.7 \%)$ was considerably higher than the $3.9 \%$ prevalence in the US population (37). A similar pattern was found for lifetime prevalence of AUD and DUD. While the lifetime prevalence of AUD in our study was lower than that in the general Norwegian or US population, the lifetime prevalence of DUD was considerably higher $(34,35,36,38)$.

Our findings demonstrate the need to distinguish between different types of SUD in the understanding of comorbidity in patients with ADHD. The findings that DUD, in contrast to AUD, was far more prevalent than in the general population, as well as our findings that DUD, but not AUD, was associated with increased ED and ADHD symptom severity, corresponds to several findings in the literature. First, genome wide association studies have shown strong genetic correlations between ADHD and DUD $(39,40)$, while some genetic factors contributing to the risk of developing AUD are negatively correlated with ADHD (41). Second, there may be some shared environmental determinants for ADHD and DUD (40) for example maternal DUD (42). Third, it has been suggested that drug dependence, especially the misuse of amphetamine and cannabis, is the result of self-medication related to ADHD symptoms $(43,44,45)$. In our sample, amphetamine and cannabis were the preferred substances of misuse.

The higher prevalence rates of AUD and DUD in men compared to women are in accordance with gender differences in the general population $(34,35,36,37)$. In line with others we find that women reported higher levels of hyperactivity-impulsivity (46) and ED (47) compared with men. This is still consistent with our findings that hyperactivity-impulsivity and ED in both women and men are associated with DUD.

Our observation that DUD was associated with ED is consistent with findings that ED in general increases the risk of developing and maintaining drug addiction (48). DUD typically appears later in life than ADHD and ED, suggesting that DUD is modified by ADHD and ED, rather than vice versa. Nevertheless, it is possible that DUD may reinforce the symptoms of both ADHD and ED.

\section{Methodological considerations}

Patients attended to a private, not governmental funding ADHD clinic may not be representative for patients with ADHD in general. They may have a higher socio-economic status, compared to public outpatient clinics or hospitals. Also, the prevalence of morbidity may not be representative for the total ADHD patient population. Still, the reported prevalence rates in our study were similar to recently reported prevalence rates for the total Norwegian population (17).

The cross-sectional design limits the interpretation of causal relationships. 


\section{Conclusions}

In this study of adult ADHD patients, we found a high prevalence of DUD. DUD was independently associated with both higher symptom levels of hyperactivity-impulsivity and ED. Thus, a co-morbid DUD should be considered in adult ADHD patients, particularly among individuals with high levels of hyperactive-impulsive ADHD core symptoms or ED.

\section{Clinical implications}

The causal mechanisms of the relationship between ADHD and DUD are not known, but self-medication for hyperactivity-impulsivity and ED is a likely possibility. Thus, early recognition and targeted interventions may be necessary to prevent the negative consequences of ADHD.

\section{Abbreviations}

ADHD: Attention Deficit Hyperactivity Disorder

ED: Emotional Dysregulation

MINI: Mini International Neuropsychiatric Interview

ASRS: Adult ADHD Self Report Scale.

DIVA: Diagnostisch Interview Voor ADHD bijvolwassenen

SUD: Substance Use Disorder

DUD: Drug Use Disorder

AUD: Alcohol Use Disorder

\section{Declarations}

Ethics approval and consent to participate: The study was approved by the REK -Regional Committees for Medical and Health Research Ethics, South-East D, Norway, 2015/426. Written consent to participate was obtained from all participants.

Consent for publication: Not applicable

Availability of data and materials: Data are from a private psychiatric outward in Oslo. Public availability would compromise privacy of the respondents. According to the approval from the Norwegian Regional committees for medical and health research ethics, the data is to be stored properly and in line with the Norwegian Law of privacy protection. However, anonymized data is freely available to interested 
researchers upon request, pending ethical approval from the ethics committee. Interested researchers can contact project leader Espen Anker (espen.anker@online.no) with requests for the data.

Competing interests: EA has received speaker honoraria from Shire, $\mathrm{JH}$ has received speaker honoraria from Lilly, Shire, HB Pharma, Medice and Biocodex. TH report no competing interest.

Funding: This work was economically supported by NevSom. Oslo University Hospital, grant number 51379. The funder had no other role in the study or writing the manuscript.

Authors' contributions: EA and TH designed the study. EA collected and analyzed the data. EA, JH and TH participated actively in the writing of the manuscript and all authors approved the final draft.

Acknowledgements: Not applicable

\section{References}

1. DSM-5 2013: Diagnostic and statistical manual of mental disorders (DSM-5®). 2013: American Psychiatric Association. Pub. 2. Thapar A. Cooper M. Eyre o. Langley K Practitioner Review: What have we learnt about the causes of ADHD? Journal of Child Psychology and Psychiatry 54:1 (2013), pp 3-16 https://doi.org/10.1111/j.1469-7610.2012.02611.x 3. Faraone SV, Larsson H. Genetics of attention deficit hyperactivity disorder. Molecular psychiatry. 2019 Apr;24(4):562. 4. Archer T, Oscar-Berman M \& Blum K. Epigenetics in developmental disorder: ADHD and endophenotypes. Journal of genetic syndrome \& gene therapy, 2011, 2(104). 5. Fayyad J. De Graaf R, Kessler R, Alonso J, Angermeyer M, Demyttenaere K, De Girolamo G, Haro JM, Karam EG, Lara C, Lépine JP, Ormel J, Posada-Villa J, Zaslavsky AM, Jin R., Crossnational prevalence and correlates of adult attention-deficit hyperactivity disorder. Br J Psychiatry, 2007. 190: p. 402-9. 6. Kessler RC, Adler L, Barkley R, Biederman J, Conners CK, Demler O, Faraone SV, Greenhill LL, Howes MJ, Secnik K, Spencer T, Ustun TB, Walters EE, Zaslavsky AM., The prevalence and correlates of adult ADHD in the United States: results from the National Comorbidity Survey Replication. Am J Psychiatry, 2006. 163(4): p. 716-23. 7. Willcutt EG, Nigg JT, Pennington BF, Solanto MV, Rohde LA, Tannock R, . . Lahey BB. Validity of DSM-IV attention deficit/hyperactivity disorder symptom dimensions and subtypes. Journal of Abnormal Psychology, 2012. 121(4), 991-1010. http://dx.doi.org/10.1037/a0027347 8. Cortese S, Faraone SV, Bernardi S, Wang S, Blanco C. Gender differences in adult attention-deficit/hyperactivity disorder: results from the National Epidemiologic Survey on Alcohol and Related Conditions (NESARC). J Clin Psychiatry. 2016 Apr;77(4):e421-8. doi: 10.4088/JCP.14m09630. 9. Biederman J, Monuteaux M, Mick E, Spencer T, Wilens T, Silva J, Snyder L, Faraone SV. Young adult outcome of attention deficit hyperactivity disorder: a controlled 10-year followup study. Psychol Med 2006; 36:167-179. http://dx.doi.org/10.1017/S0033291705006410 10. Wilens TE, Biederman J, Mick E, Faraone SV, Spencer T. Attention-deficit/hyperactivity disorder (ADHD) is associated with early-onset substance use disorders. J Nerv Ment Dis 1997; 185:475-82. 11. Wilens TE. The nature of the relationship between attention-deficit/hyperactivity disorder and substance use. The Journal of clinical psychiatry. 2007;68:4-8. 12. Wilens TE, Martelon M, Joshi G, Bateman C, Fried R, Petty C, Biederman J. Does ADHD predict substance-use disorders? A 10-year follow-up study of young adults 
with ADHD. J Am Acad Child Adolesc Psychiatry. 2011 Jun; 50(6):543-53. 13. van Emmerik-van Oortmerssen K, van de Glind G, van den Brink W, Smit F, Crunelle CL, Swets M, Schoevers RA: Prevalence of attention-deficit hyperactivity disorder in substance use disorder patients: a meta-analysis and metaregression analysis. Drug Alcohol Depend 2012; 122: 11-9. 14. van de Glind G, Konstenius M, Koeter MWJ, et al. Variability in the prevalence of adult ADHD in treatment seeking substance use disorder patients: results from an international multi-center study exploring DSM-IV and DSM- 5 criteria. Drug Alcohol Depend 2014; 134:158-166. DOI:10.1016/j.drugalcdep.2013.09.026 15. Charach A, Yeung E, Climans T, Lillie E: Childhood attention-deficit/hyperactivity disorder and future substance use disorders: comparative meta-analyses. J Am Acad Child Adolesc Psychiatry 2011; 50: 9-21 DOI:10.1016/j.jaac.2010.09.019 16. Crunelle CL, van den Brinkc W, Moggid F, Konsteniuse M, Francke J, Frances R. Levinf Geurt van de Glindg Zsolt Demetrovicsh Corné Coetzeei Mathias Ludererj Arnt Schellekensk ICASA consensus group Frieda Matthysa. International Consensus Statement on Screening, Diagnosis and Treatment of Substance Use Disorder Patients with Comorbid Attention Deficit/Hyperactivity Disorder. Eur Addict Res 2018;24:43-51 DOI: 10.1159/000487767 17. Solberg BS, Halmøy A, Engeland A, Igland J, Haavik J, Klungsøyr K.: Gender differences in psychiatric comorbidity: a population-based study of 40000 adults with attention deficit hyperactivity disorder. Acta Psychiatr Scand 2018: 137: 176-186, DOI: 10.1111/acps.12845 18. Shaw P, Stringaris A, Nigg J, Leibenluft E. Emotion dysregulation in attention deficit hyperactivity disorder. Am J Psychiatry, 2014. 171(3): p. 276-93. PMID: 24480998 PMCID: PMC4282137 DOI: 10.1176/appi.ajp.2013.13070966 19. Connor DF, Steeber J, McBurnett K. A review of attention-deficit/hyperactivity disorder complicated by symptoms of oppositional defiant disorder or conduct disorder. Journal of Developmental \& Behavioral Pediatrics. 2010 Jun 1;31(5):427-40. 20. Landaas ET, Halmøy A, Oedegaard KJ, Fasmer OB, Haavik J. The impact of cyclothymic temperament in adult ADHD. J Affect Disord. 2012 Dec 15;142(1-3):241-7. Doi:

10.1016/j.jad.2012.04.034. 21. Barkley RA, Fischer M. The unique contribution of emotional impulsiveness to impairment in major life activities in hyperactive children as adults. Journal of the American Academy of Child \& Adolescent Psychiatry. 2010 May 1;49(5):503-13. 22. Faraone SV, Rostain AL, Blader J, Busch B, Childress AC, Connor DF, Newcorn JH. Practitioner Review: Emotional dysregulation in attention-deficit/hyperactivity disorder-implications for clinical recognition and intervention. Journal of Child Psychology and Psychiatry. 2019 Feb;60(2):133-50.. 23. Aldao A, Gee DG, De Los Reyes A, \& Seager I. (2016). Emotion regulation as a transdiagnostic factor in the development of internalizing and externalizing psychopathology: Current and future directions. Development and psychopathology, 28(4pt1), 927-946. 24. Schreiber LR, Grant JE, \& Odlaug BL (2012). Emotion regulation and impulsivity in young adults. Journal of psychiatric research, 46(5), 651-658. 25. Sobanski E, Banaschewski T, Chen W, Holtmann M, Asherson P, Stringaris A, Buitelaar J, Franke B, Sergeant J, Sonuga-Barke E, Taylor E, Ebstein R, Gill M, Miranda A, Oades R, Roeyers H, Rothenberger A, Steinhausen HC, Mulas F, Anney R, Krumm B, Faraone S. Emotional lability in children and adolescents with Attention Deficit / Hyperactivity Disorder (ADHD): Clinical correlates and familial prevalence. Journal of Child Psychology and Psychiatry, 2010, 51, 915-923 doi.org/10.1111/j.1469-7610.2010.02217.x 26. Kooij, J. J. S., \& Francken, M. H. (2010). Diagnostic interview for ADHD in adults 2.0 (DIVA 2.0). Adult ADHD: Diagnostic assessment and treatment, 33-99. 27. Sheehan DV, Lecrubier Y, Sheehan KH, et al. The validity of the Mini International 
Neuropsychiatric Interview (MINI) according to the SCID-P and its reliability. Eur Psychiatry 1997;12:23241. 28. Sheehan DV, Lecrubier Y, Sheehan KH, Amorim P, Janavs J, Weiller E, Hergueta T, Baker R, Dunbar GC. The Mini-International Neuropsychiatric Interview (MINI): the development and validation of a structured diagnostic psychiatric interview for DSM-IV and ICD-10. The Journal of clinical psychiatry. 1998. 29. Silverstein MJ, Alperin S. Faraone SV, Kessler RC, and Adler LA: Test-retest reliability of the adult ADHD Self-Report Scale (ASRS) v1.1 Screener in non-ADHD controls from a primary care physician practice. Family Practice, Volume 35, Issue 3, June 2018, p336-341 doi.org/10.1093/fampra/cmx115 30. Fredriksen M, Dahl AA, Martinsen EW, Klungsøyr O, Haavik J, Peleikis DE. Effectiveness of one-year pharmacological treatment of adult attention-deficit/hyperactivity disorder (ADHD): an open-label prospective study of time in treatment, dose, side-effects and comorbidity. Eur Neuropsychopharmacol. 2014 Dec;24(12):1873-84. doi: 10.1016/j.euroneuro.2014.09.013. Epub 2014 Oct 18. 31. Barkley R. ADHD in adults: Comorbidity and adaptive impairments. (1997) NIMH Grant number1R01MH054509-01A2. 32. Barkley RA and Murphy KR: Deficient emotional self-regulation in adults with Attention deficit Hyperactive Disorder (ADHD): The Relative Contribution of Emotional Impulsiveness and ADHD symptoms to Adaptive Impairment in Major Life Activities. J. ADHD Related Disorders (2010) vol 1, 5-28 33. Surman CB, Biederman J, Spencer T, Miller CA, Petty CR, Faraone SV. Neuropsychological deficits are not predictive of deficient emotional self-regulation in adults with ADHD. Journal of Attention Disorders. 2015 Dec;19(12):1046-53. 34. Grant BF, Goldstein RB, Saha TD, Chou SP, Jung J, Zhang H, Pickering RP, Ruan WJ, Smith SM, Huang B, Hasin DS. Epidemiology of DSM-5 alcohol use disorder: results from the National Epidemiologic Survey on Alcohol and Related Conditions III. JAMA psychiatry. 2015 Aug 1;72(8):757-66. 35. Rehm J, Room R, van den Brink W, \& Jacobi F. Alcohol use disorders in EU countries and Norway: an overview of the epidemiology. European Neuropsychopharmacology (2005) 15,4,377-388 doi.org/10.1016/j.euroneuro.2005.04.005 36. Bratberg GH, Wilsnack SC, Wilsnack R, Haugland SH, Krokstad S, Sund ER and Bjørngaard JH: Gender differences and gender convergence in alcohol use over the past three decades (1984-2008), The HUNT Study, Norway. BMC Public Health. 2016 Aug 5;16:723. doi:10.1186/s12889-016-3384-3. 37. Grant BF, Saha TD, Ruan WJ, Goldstein RB, Chou SP, Jung J, Zhang $\mathrm{H}$, Smith SM, Pickering RP, Huang B, Hasin DS. Epidemiology of DSM-5 drug use disorder: results from the National Epidemiologic Survey on Alcohol and Related Conditions-III. JAMA psychiatry. 2016 Jan 1;73(1):39-47. 38. Kringlen E, Torgersen S, Cramer V. A Norwegian psychiatric epidemiological study. American journal of psychiatry. 2001 Jul 1;158(7):1091-8. 39. Demontis D, Walters RK, MartinJ, Mattheisen M, Als TD, Agerbo E, ... \& Cerrato F. (2019). Discovery of the first genome-wide significant risk loci for attention deficit/hyperactivity disorder. Nature genetics, 51(1), 63. doi:

https://doi.org/10.1101/145581 40. Wang K, Gaitsch H, Poon H, Cox NJ, Rzhetsky A. Classification of common human diseases derived from shared genetic and environmental determinants. Nature genetics. 2017 Sep;49(9):1319-1325 41. Sanchez-Roige S, Fontanillas P, Elson SL, 23andMe Research Team, Gray JC, de Wit H, Davis LK, MacKillop J, Palmer AA. Genome-wide association study of alcohol use disorder identification test (AUDIT) scores in 20328 research participants of European ancestry. Addiction biology. 2019 Jan;24(1):121-31. 42. Thapar A, Langley K, Asherson P and Gill M. Gene-environment interplay in attention-deficit hyperactivity disorder and the importance of a developmental perspective. The British journal of psychiatry Volume 190, Issue 1January (2007), pp. 1-3. 43. Wilens TE. Impact of ADHD and its 
treatment on substance abuse in adults. Journal of Clinical Psychiatry. 2004 Mar 1;65:38-45. 44. Wilens TE, Adamson J, Sgambati S, Whitely J, Santry A, Monuteaux MC, et al. Do individuals with ADHD selfmedicate with cigarettes and substances of abuse? Results from a controlled family study of ADHD. Am J Addict (2007) 16 (Suppl.1):14-21. 45. Brandt A. Rehm J. \& Lev-Ran S. Clinical Correlates of Cannabis Use Among Individuals With Attention Deficit Hyperactivity Disorder. The Journal of nervous and mental disease, (2018). 206(9), 726-732. 46. Vildalen VU, Brevik EJ, Haavik J, Lundervold AJ. Females with ADHD report more severe symptoms than males on the adult ADHD self-report scale. Journal of attention disorders. 2019 Jul;23(9):959-67. 47. Robison RJ, Reimherr FW, Marchant BK, Faraone SV, Adler LA, \& West SA. Gender differences in 2 clinical trials of adults with attention-deficit/hyperactivity disorder: a retrospective data analysis. The Journal of clinical psychiatry, (2008). 69(2), 213-221. 48. Cheetham A, Allen NB. Yücel M, Lubman DI. The role of affective dysregulation in drug addiction. Clinical Psychology Rev. (2010),30,6,621-34

\section{Tables}

Table 1: Emotional Dysregulation (ED) questionnaire.

\begin{tabular}{|c|c|c|c|c|}
\hline Emotional Dysregulation items: & $\begin{array}{l}\text { Never or } \\
\text { Rarely }\end{array}$ & $\begin{array}{l}\text { Some- } \\
\text { times }\end{array}$ & Often & $\begin{array}{l}\text { Very } \\
\text { often }\end{array}$ \\
\hline 1. Quick to get angry or become upset & 0 & 1 & 2 & 3 \\
\hline 2. Easily frustrated & 0 & 1 & 2 & 3 \\
\hline 3. Overreact emotionally & 0 & 1 & 2 & 3 \\
\hline $\begin{array}{l}\text { 4. Easily excited by activities going on } \\
\text { around me }\end{array}$ & 0 & 1 & 2 & 3 \\
\hline 5. Lose my temper & 0 & 1 & 2 & 3 \\
\hline 6. Argue with others & 0 & 1 & 2 & 3 \\
\hline 7. Am touchy or easily annoyed by others & 0 & 1 & 2 & 3 \\
\hline 8. Am angry or resentful & 0 & 1 & 2 & 3 \\
\hline
\end{tabular}

Eight items from the Current Behavior Scale - Self Report questionnaire $(31,32,33)$.

Table 2. Demographic characteristics, ADHD symptom severity, and emotional dysregulation in 585 adult patients diagnosed with ADHD in a psychiatric clinic specialized in examination and treatment of ADHD. When others not specified, figures are given as numbers (percentage). 


\begin{tabular}{|l|c|c|c|}
\hline & Men: 317 & Women: 268 & All patients: 585 \\
\hline $\begin{array}{l}\text { Age in years, mean (SD): } \\
\text { range: }\end{array}$ & $\begin{array}{c}36.2(11.5) \\
18-67\end{array}$ & $\begin{array}{c}37.5(11.2) \\
18-69\end{array}$ & $\begin{array}{c}36.8(11.4) \\
18-69\end{array}$ \\
\hline Married or cohabitant: & $143(45.1)$ & $107(39.9)$ & $250(42.7)$ \\
\hline Living with children: & $110(34.7)$ & $117(43.7) *$ & $227(38.8)$ \\
\hline Years of education: $\leq 12$ & $172(54.3)$ & $129(48.1)$ & $301(51.5)$ \\
\multicolumn{1}{|c|}{ 13-15: } & $121(38.2)$ & $108(40.3)$ & $229(39.1)$ \\
& $24(7.6)$ & $31(11.6)$ & $55(9.4)$ \\
\hline Work participation & $193(60.9)$ & $149(55.6)$ & $342(58.5)$ \\
\hline ADHD symptom severity, mean (SD) & $50.4(9.5)$ & $52.3(9.5) * *$ & $51,4(9.5)$ \\
Inattention, mean (SD) & $27.0(4.6)$ & $27.8(4.9) *$ & $27.4(4.7)$ \\
Impulsivity or hyperactivity, mean (SD) & $23.3(6.6)$ & $24.7(6.5) * *$ & $24.0(6.6)$ \\
\hline Emotional Dysregulation, mean (SD) & $11.0(5.6)$ & $13.4(5.3) * * *$ & $12.1(5.6)$ \\
\hline
\end{tabular}

ADHD symptom severity was assessed by ASRS. Emotional Dysregulation was assessed by eight items from CBS-SR. $* \mathrm{p}<0.05, * * \mathrm{p}<0.01, * * * \mathrm{p}<0.001$. (Women compared with men.)

Table 3. Prevalences of alcohol or drug use disorders in 585 adult patients diagnosed with ADHD in a psychiatric clinic specialized in examination and treatment of ADHD. Figures are given in numbers (percentage). 


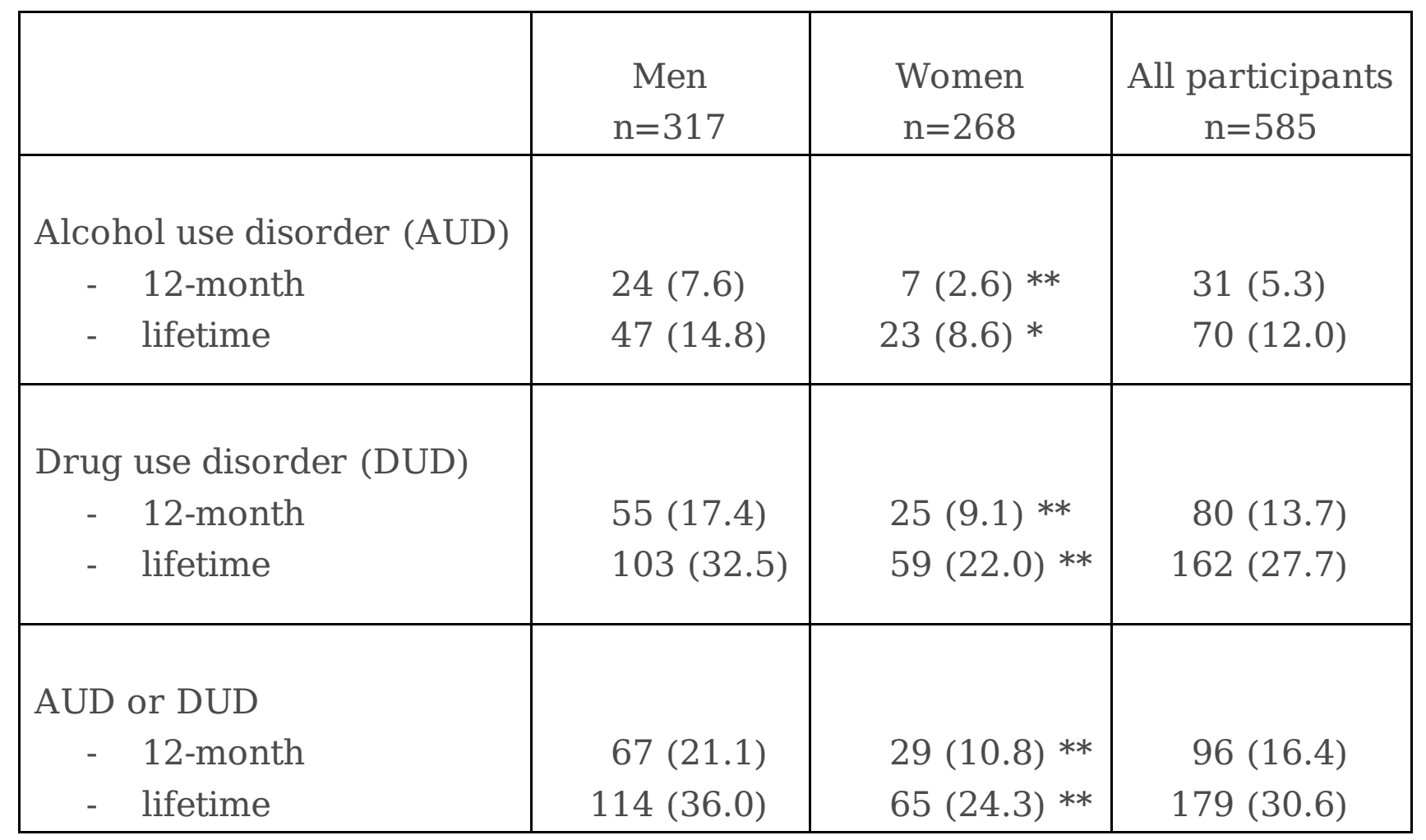

$* \mathrm{p}<0.05, * * \mathrm{p}<0.01$. (Women compared with men, Chi square)

Table 4. Associations between age, gender, ADHD relevant clinical characteristics, and outcome of lifetime alcohol use disorder (AUD) in a clinical sample of 585 adult ADHD patients, non-adjusted and adjusted analysis.

\begin{tabular}{|l|c|c|c|c|c|c|}
\hline & \multicolumn{3}{|c|}{ Non-Adjusted } & \multicolumn{3}{c|}{ Adjusted } \\
\hline & OR & $95 \%$ CI & p-value & OR & $95 \%$ CI & p-value \\
\hline Age (increasing in 10 years) & 1.32 & $1.06-1.64$ & 0.013 & 1.32 & $1.05-1,64$ & 0.016 \\
\hline Gender (men v. women) & 1.94 & $1.14-3.31$ & 0.015 & 2.19 & $1.27-3.77$ & 0.005 \\
\hline Inattentive & 1.03 & $0.98-1.09$ & 0.27 & 1.01 & $0.95-1.07$ & 0.82 \\
\hline Hyperactivity- Impulsivity & 1.05 & $1.01-1.09$ & 0.027 & 1.03 & $0.98-1.08$ & 0.24 \\
\hline Emotional Dysregulation & 1.05 & $1.00-1.09$ & 0.06 & 1.04 & $0.98-1.10$ & 0.16 \\
\hline
\end{tabular}


Table 5. Associations between age, gender, ADHD relevant clinical characteristics, and outcome of lifetime drug use disorder (DUD) in a clinical sample of 585 adult ADHD patients, non-adjusted and adjusted analysis.

\begin{tabular}{|l|c|c|c|c|c|c|}
\hline & \multicolumn{3}{|c|}{ Non-Adjusted } & \multicolumn{3}{c|}{ Adjusted } \\
\hline & OR & $95 \%$ CI & p-value & OR & $95 \%$ CI & p-value \\
\hline Age (increasing in 10 years) & 1.10 & $0.94-1.29$ & 0.24 & 1.08 & $0.92-1.27$ & 0.36 \\
\hline Gender (men v. women) & 1.71 & $1.18-2.49$ & 0.005 & 2.01 & $1.36-2.97$ & $<0.001$ \\
\hline Inattentive & 1.02 & $0.97-1.05$ & 0.77 & 0.97 & $0.93-1.02$ & 0.21 \\
\hline Hyperactivity-Impulsivity & 1.04 & $1.02-1.07$ & 0.003 & 1.04 & $1.01-1.08$ & 0.021 \\
\hline Emotional Dysregulation & 1.05 & $1.01-1.08$ & 0.006 & 1.05 & $1.01-1.09$ & 0.019 \\
\hline
\end{tabular}

